\title{
Aspectos Políticos, Econômicos e Institucionais Presentes na Formação do Polo Tecnológico de Campinas (1965-1985) ${ }^{1}$
}

\author{
Political, technical, and institutional factors present in the creation \\ of the Campinas Technological Hub (1965-1985)
}

\author{
WILLIAN GAMA DOS SANTOS \\ Centro Interunidades de História da Ciência | CHC/USP
}

\begin{abstract}
RESUMO Nesse artigo apresentamos o processo histórico de formação do Polo Tecnológico de Campinas. Buscamos relacionar o contexto local, sua vinculação direta com a Universidade de Campinas e mais precisamente com os trabalhos desenvolvidos no Instituto de Física dessa universidade. Também pretendemos analisar a influência direta do Estado, seu alcance, e limites presentes nas iniciativas propostas pelo regime militar e suas políticas desenvolvimentistas.
\end{abstract}

Palavras-chave polos tecnológicos - políticas de ciência e tecnologia - desenvolvimento - ditadura militar brasileira

\begin{abstract}
In this article, we present the historical process of creation of the Technological Hub of Campinas. We seek to relate the local historical context, its direct link with the University of Campinas and more precisely with the work developed in the University's Institute of Physics. We also try to analyze the direct influence of the state, its scope, and limits present in the initiatives proposed by the military regime and its developmentalist policies.
\end{abstract}

Keywords technological hubs - science and technology policy - development-Brazilian military dictatorship

\section{Introdução}

A íntima relação entre planejamento econômico e políticas para a ciência e tecnologia se tornou uma constante a partir da implantação do regime militar. Principalmente após o governo do general Emílio Garrastazu Médici (19691974), o Estado brasileiro mobilizou todos os esforços do planejamento estratégico do governo, presentes no I PND, no sentido de construir um modelo alternativo de desenvolvimento que permitisse o rápido crescimento econômico do país e sua consequente modernização. Nesse processo desenvolvimentista, incorporou-se o investimento a C\&T, e principalmente a P\&D, como fator de estímulo a modernização da infraestrutura do país² .

Perceber o impacto dessa nova política para a ciência e tecnologia exige a análise de como tais demandas influenciaram determinantemente 0 andamento das atividades científicas nos laboratórios e instituições de ensino superior no Brasil. Nesse artigo propomos analisar o surgimento do Polo Tecnológico da região de Campinas como resultado desse 
processo, identificar os vetores institucionais que permitiram a estruturação de parte das iniciativas desenvolvimentistas na região e quais foram os resultados apresentados nos anos finais do regime militar para a região de Campinas.

\section{Estruturação do Polo Tecnológico de Campinas: pesquisa e desenvolvimento e Instituições de Ensino Superior a serviço do Modelo Brasileiro de Desenvolvimento}

As demandas sociais a favor de uma universidade na cidade de Campinas podem ser resgatadas pelo menos até 0 ano de 1935. Nesse ano, a Seção de Urbanismo e Arquitetura da prefeitura iniciou o planejamento de um projeto que visava modernizar as estruturas urbanas da cidade. Dentro desse planejamento estava colocada a demanda por uma universidade voltada ao ensino normal, comercial e técnico ${ }^{3}$. Também data desse período o surgimento de reivindicações a favor de uma faculdade voltada ao ensino de medicina. Tal faculdade chegou a ser criada por lei, em 1959, contudo nunca foi instituída conforme planejado 4 .

Em 28 de dezembro de 1962, em um dos últimos atos de seu mandato, o governador Carvalho Pinto criou a Universidade de Campinas (UNICAMP), que na prática, até 0 ano de 1966, era constituída apenas pelo curso de Medicina ${ }^{5}$.

A estruturação de fato da universidade começou a ser efetuada apenas no final do ano de 1965. Nesse ano, 0 médico Zeferino Vaz foi convidado pelo governador Laudo Natel a assumir os trabalhos de organização da universidade através da Comissão de Organização da Universidade, da qual foi nomeado presidente ${ }^{6}$. Em 1969, Vaz assumiu a reitoria da universidade recém-criada, cargo que manteve até 1978.

Antes de avançarmos, é preciso entender a importância de Zeferino Vaz nesse processo e o caráter de sua atuação como reitor à frente da universidade, acreditamos que as principais características de sua gestão já estavam definidas desde as primeiras iniciativas tomadas por sua reitoria, vamos analisar em detalhe esses primeiros momentos e a partir de então verificar o impacto da atuação do reitor no encaminhamento do polo tecnológico na cidade de Campinas.

Para esclarecermos a escolha de Zeferino Vaz para a reitoria da universidade é preciso resgatar a biografia desse acadêmico e administrador universitário. Vaz consolidou uma posição de respeito dentro da academia paulista e conseguiu se cercar de apoiadores influentes durante sua longa trajetória em instituições universitárias. Sua carreira se iniciou no Instituto Biológico (IB), na cidade de São Paulo. Posteriormente ocupou a cadeira de Zoologia Médica e Parasitologia da Faculdade de Medicina Veterinária da Universidade de São Paulo (FMVZ/USP), nessa faculdade chegou a ocupar ocupou o cargo de diretor entre 1936 a 1947. Ao participar do Conselho Universitário por vinte e sete anos, inclusive como diretor, chegou a ter considerável destaque - em depoimento revela ter influência a ponto de ser um "fazedor de reitores" ${ }^{\prime \prime}$ - também atuou na instalação bem-sucedida da Faculdade de Medicina na cidade de Ribeirão Preto.

Além do respeito de seus pares na academia, Zeferino Vaz contava com livre trânsito no gabinete de diversos governadores do Estado de São Paulo, como Lucas Nogueira Garcez, que o escolheu para a diretoria da Faculdade de Medicina de Ribeirão Preto, e Laudo Natel, que o chamou para planejar e estruturar a Universidade de Campinas.

Zeferino Vaz também mantinha bom relacionamento com os dirigentes da política paulista, inclusive era visto com simpatia pela cúpula do regime militar. Colaborador desde às vésperas do golpe de 1964 - momento onde atuou garantindo 0 transporte de tropas através do fornecimento de 250 peruas e depósitos de gasolina - foi convocado pelo presidente Castello Branco a ser interventor federal na Universidade de Brasília ${ }^{9}$ (UnB), posto que ocupou durante um ano e quatro meses. Nesse episódio se aponta a associação com atividades de repressão a funcionários, professores e alunos dessa instituição.

Tirante sua orientação ideológica favorável ao ambiente autoritário instalado pelo Golpe de 1964, a escolha de Zeferino Vaz também está ligada à sua considerável habilidade de gestor acadêmico e à sua visão arrojada quanto 
à atuação da universidade no país. 0 sucesso em Ribeirão Preto, local onde conseguiu atrair cientistas de renome e estruturou um curso de medicina moderno e progressista ${ }^{10}$, abriu as portas para que ele pudesse planejar livremente uma universidade baseada nos ideais de integração do pensamento, racionalização dos espaços e íntima relação com as demandas públicas e privadas ${ }^{11}$. Podemos ver parte desse ideal materializado na própria distribuição territorial das unidades e institutos, conforme planejado no projeto arquitetônico e urbanístico da Unicamp. Ambicioso em suas pretensões, Zeferino Vaz buscava como referência a Ágora da polis grega ${ }^{12}$.

A ousadia de pensamento e habilidade de negociação permitiram que o reitor atraísse intelectuais das mais diversas tendências ideológicas. Em poucos anos, Zeferino Vaz conseguiu formar uma estrutura universitária considerável. Entre esses intelectuais podemos citar desde físicos celebrados na época, como César Lattes, passando por economistas, como Maria da Conceição Tavares e Luiz Gonzaga Belluzo, e diversos outros acadêmicos que despontavam como referência em seus respectivos campos de atuação.

Em um momento de repressão política e ideológica, inclusive com a interferência do SNI (Serviço Nacional de Inteligência) nas universidades de todo o país, Zeferino Vaz conseguiu abrir espaços de negociação, e em algumas situações, inclusive chegou a barganhar com a linha dura do regime - por exemplo, em troca de imunidade dentro do espaço universitário, Vaz contratou coronéis aposentados do SNI como professores titulares da disciplina Problemas Brasileiros presente em cursos do Instituto de Filosofia e Ciências Humanas (IFCH/Unicamp) ${ }^{13}$. Tal decisão provocou constrangimentos e embaraços aos professores e alunos do IFCH devido ao convívio forçado com figuras claramente associadas ao regime ditatorial vigente, entretanto abriu perspectivas singulares para os membros da universidade. Como consequência da boa aceitação que o esse reitor tinha por parte do regime militar, e devido a sua capacidade de manobra e negociação, foi garantido espaços de relativa liberdade intelectual dentro dos muros da UNICAMP mesmo durante o período de maior repressão ideológica da Ditadura Militar.

Iniciados os projetos de construção dos prédios e contratado o primeiro grupo de professores, Zeferino Vaz fez valer seu livre trânsito dentro do regime militar e partiu em busca de financiamento para o desenvolvimento da universidade. Ao recorrer ao então secretário de planejamento do Estado de São Paulo, Dilson Funaro, conseguiu Cr\$ 5 milhões para equipamentos e edifícios. Também foi colocado em contato com Marcos Viana, do BNDE, e José Pelúcio Ferreira, da Finep. Com a demora do repasse do aporte financeiro, o reitor procurou diretamente o ministro Delfim Netto, com o qual tinha relações desde o período em que esteve no Conselho Universitário da USP. Delfim Netto agilizou o processo de repasses dos recursos e garantiu que as portas da Finep e da Secretaria de Tecnologia Industrial estivessem sempre abertas ${ }^{14}$.

Podemos também elencar as contribuições do CNPO e da Fapesp. Além de disponibilizarem recursos para a construção de laboratórios, essas instituições chegaram, inclusive, a pagar a viagem de volta de diversos professores que até então estavam trabalhando em instituições de ensino e pesquisa no estrangeiro ${ }^{15}$.

Além da boa vontade do Regime em relação a sua pessoa, Zeferino Vaz contou com um ambiente favorável na política de financiamento à C\&T que vigorava naquela conjuntura, pois a partir do governo Costa e Silva (1967-1969), o Modelo Brasileiro de Desenvolvimento incorporou o incentivo a P\&D e C\&T como fator de estímulo ao crescimento econômico. Pesquisas que proporcionassem aplicações e inovações tecnológicas passaram a ser largamente subsidiadas, a Unicamp se aproveitou descomedidamente desse ambiente para se estruturar.

Ainda sobre a contratação de professores, o momento histórico favoreceu a incorporação de pesquisadores e docentes que se encontravam radicados no exterior. 0 fim da década de 1960 corresponde ao período onde o governo procurou estancar o que foi nomeado como "fuga de cérebros" pela imprensa da época ${ }^{16}$.

Parte da historiografia que analisou esse período identificou que ao final dos anos 60 foi criada uma força-tarefa pelo governo federal, esse grupo foi responsável por atrair talentos que pudessem concretizar a aposta do governo em impulsionar as metas desenvolvimentistas com investimentos em C\&T. 0 principal objetivo dessa força tarefa formada por diplomatas, políticos e até membros das forças armadas, era o de demonstrar aos cientistas brasileiros que o Brasil pós-Al-5 tinha se convertido em um lugar seguro para o pesquisador disposto a colocar o projeto do "Brasil Potência" em 
curso. Também demonstraram, em inúmeras reuniões e encontros com esses cientistas, que o Estado estava disposto a disponibilizar recursos e investimentos para projetos no âmbito da P\&D e C\&T, além de ressaltar os consequentes ganhos pessoais e institucionais presentes nessa oferta.

A intenção do governo, quando promove tal campanha de apoio explícito aos cientistas que se encontravam no exterior, era atrair pesquisadores altamente qualificados que pudessem colocar em marcha uma nova fase do desenvolvimento econômico brasileiro. Nessa nova fase, era impreterível a superação de obstáculos estruturais a partir do desenvolvimento da ciência e tecnologia nacionais. Decidido a superar os entraves tecnológicos que dificultavam o projeto desenvolvimentista, o Estado brasileiro passou a investir pesadamente no retorno desses pesquisadores. Planeja-se, com a chegada dessa nova leva de cientistas que estavam em contato direto com a alta tecnologia dos países desenvolvidos, a solução dos diversos problemas de infraestrutura, assim como a realização de projetos voltados a tecnologias adaptadas às necessidades nacionais.

0 reflexo dessa conjuntura é claramente percebido no momento de constituição do corpo docente da Unicamp. Conforme pudemos conferir em nossa pesquisa, essas iniciativas foram determinantes para a incorporação de um grupo de engenheiros e físicos, que ao final da década de 1960 trabalhavam nos Estados Unidos, no Bell Laboratories, e que a partir de então passaram a fazer parte do Instituto de Física Gleb Wataghin (IFGW/Unicamp). Nesse processo, mais uma vez é notada a participação decisiva no reitor Zeferino Vaz na atração desses pesquisadores para a Unicamp.

Um dos líderes do grupo de pesquisadores radicados nos Estados Unidos, que negociou a vinda desses cientistas para o Brasil, foi o físico Rogério Cezar de Cerqueira Leite. Junto ao seu colega, Sérgio Porto, que além de pesquisador no Bell Laboratories, também era professor na Universidade do Sul da Califórnia (USC), receberam diversas visitas de embaixadores, e até a visita do então senador da ARENA, Arnon de Melo. 0 objetivo dessas reuniões era o de apresentar toda a estrutura de financiamento e apoio planejada pelo governo federal, abrindo as portas das instituições de pesquisa e universidades a esses cientistas ${ }^{17}$.

Instigados pela possibilidade de retornar ao país, e de alguma maneira tocados pelo otimismo nacionalista disseminado pelo regime militar, o grupo de pesquisadores ligados ao Bell Laboratories procurou contatos que permitissem o reingresso do grupo à academia científica brasileira. Percebendo a janela de oportunidade aberta, Zeferino Vaz abriu negociação com a equipe de cientistas e conseguiu atrair esses pesquisadores para a Unicamp ${ }^{18}$. Poucos anos depois, das iniciativas promovidas por esse grupo surgiria a espinha dorsal do polo tecnológico de Campinas.

Entre 1970 e 1971, os professores, Rogério Cezar de Cerqueira Leite, Sérgio Porto, José Ellis Ripper, e outros colegas associados, foram contratados para a universidade. Ingressaram no Instituto de Física, em sua grande maioria atuando no Departamento de Estado Sólido e Ciência dos Materiais. A partir das pesquisas e ações promovidas por esse grupo a estrutura do polo tecnológico começou a se desenvolver.

Com o início dos trabalhos do Departamento de Estado Sólido e Ciências dos Materiais, diversas pesquisas tiveram início dentro da área de especialização de cada um desses cientistas. Foram privilegiadas principalmente projetos na área de semicondutores e lasers. 0 objetivo desses trabalhos era 0 de replicar pesquisas e tecnologias que os pesquisadores tiveram contato durante o período em que estiveram no Bell Laboratories ${ }^{19}$.

Um dos primeiros empreendimentos científicos que ganhou destaque nesse momento foi a pesquisa voltada a análise das possibilidades e uso de microlasers para a telecomunicação. Esse trabalho foi liderado por José Ellis Ripper, que contava com a colaboração de pesquisadores ligados a universidades estrangeiras, como Navim Ratel, do Instituto de Tecnologia da Califórnia - Estados Unidos (CalTech) e Philippe Brosson, da Universidade de Grenoble - França (UGA) ${ }^{20}$. A partir desse grupo de pesquisas, se constituiria o Laboratório de Pesquisas em Dispositivos (LPD) no Instituto de Física da Universidade de Campinas. A equipe liderada pelo professor Ripper começou a desenvolver o equipamento de microlaser, os cristais semicondutores e toda a tecnologia embarcada ainda no ano de $1971 \underline{21}$.

No cerne dessa iniciativa estava o objetivo de tornar o Brasil autossuficiente em uma tecnologia que se mostrava com alto potencial de ser aplicada em um futuro próximo. Em depoimento à imprensa, o então diretor do Instituto de 
Física, Rogério C. de Cerqueira Leite, afirmou:

O que se pretende fazer, e já se faz na Unicamp, é inicialmente auxiliar o complexo fabril a assimilar a tecnologia que nos permitirá a produção nacional no gênero. Reconhecemos naturalmente que isso não se faz em meses, mas sim em anos, e que outros grupos especializados deverão se formar, com grande sacrifício econômico para a nação $o^{22}$.

A ideia geral do programa é definida por Cerqueira Leite como "um meio de defesa para o Brasil, que em desenvolvimento, tem na pesquisa uma boa proteção ${ }^{23}$. Ainda sobre a necessidade de um alto investimento inicial, 0 cientista justifica:

O desenvolvimento se faz inicialmente por assimilação de tecnologia e, subsequentemente, por produção própria de tecnologia. Na maior parte dos setores tecnológicos o Brasil está na primeira fase. A transição para a segunda é lenta e dispendiosa ${ }^{24}$.

Os depoimentos citados acima são interessantes na medida em que demonstram que logo no início da década de 70 o ideal desenvolvimentista já era mobilizado pela comunidade científica brasileira. Ao enunciar os termos desse processo, o representante desse grupo de cientistas, inclusive, adapta o seu discurso para soar próximo aos termos enunciados pela Doutrina de Segurança Nacional. Afirmar que a P\&D tem um papel a cumprir na defesa e desenvolvimento do país, em uma conjuntura onde a Segurança Nacional era o suporte ideológico de toda estrutura de Estado vigente, não parece arbitrário. Tal discurso aponta como parte da academia procurou mobilizar as engrenagens do poder para conseguir colocar em marcha projetos voltados à C\&T.

0 esforço concentrado desses intelectuais era o de produzir um campo de pesquisa científica e tecnológica autenticamente nacional em concorrência com o desenvolvimento tecnológico do exterior. Para fazer isso, a escolha pela comunicação por laser não foi fortuita. 0 entendimento da época era de que por ser uma tecnologia relativamente nova, a defasagem tecnológica do país naquele momento era mínima, podendo ser superada graças à estrutura de P\&D que estava sendo criada ${ }^{25}$.

Para avaliarmos o engajamento da academia científica brasileira com o processo desenvolvimentista planejado pelo regime militar é preciso cautela. Defender a meta desenvolvimentista não significa necessariamente apoiar a ideologia autoritária e conservadora sustentada pelo regime militar. Pelo contrário, muitos dos cientistas e intelectuais que se mobilizam nesse processo estão principalmente voltados ao ideal do desenvolvimento de um campo de C\&T autenticamente nacional, projeto que tinha considerável tradição no Brasil, e que após anos relegado ao ostracismo pelas políticas oficiais, finalmente começava a ser incorporada às principais diretrizes do planejamento estratégico do país.

Corroboram essa tese os diversos artigos assinados por Cerqueira Leite em editoriais no jornal Folha de São Paulo entre as décadas de 70 e 80 . Nesses textos, 0 autor ataca em inúmeras ocasiões o "entreguismo" de parte do governo perante as investidas das multinacionais estrangeiras e a insuficiente defesa dos interesses nacionais no campo da economia e ciência $\underline{26}$.

Percebemos que esses pesquisadores repudiam enfaticamente a opressiva ideologia autoritária defendida na Doutrina de Segurança Nacional27. Entretanto, não se pode negar a ambivalência dessa posição, pois ao mesmo tempo em que rejeitam o caráter conservador e autoritário do regime militar, se inserem ativamente na cruzada desenvolvimentista. A impressão que nos fica é de que para os cientistas que conviviam com esse contexto político delicado, a escolha pela ciência e a tecnologia, e a defesa da meta do desenvolvimento econômico, justificariam os eventuais descaminhos repressores e antidemocráticos desse processo.

Cabe também lembrar que o início da década de 1970 corresponde ao período do chamado "Milagre Brasileiro". Nessa conjuntura não foram poucos os que realmente se entusiasmaram com as possibilidades de crescimento do país. 
Para parte considerável dos pesquisadores nacionalistas, viver esse período e não contribuir com os projetos desenvolvimentistas em curso era quase inconcebível. Tais cientistas tinham dedicado longos anos de sua formação em prol do aprimoramento da estrutura científica do país. Nesse contexto, o projeto desenvolvimentista passou a representar a oportunidade de uma geração conseguir realizar projetos largamente cultivados ${ }^{28}$.

0 Estado, ciente da oferta de uma mão de obra qualificada e imersa na ideologia nacionalista, incluiu tal material humano em sua estrutura desenvolvimentista. Ao mesmo tempo em que os veículos de comunicação, que naquela conjuntura estavam intimamente ligados aos interesses da ditadura militar, garantiram a divulgação positiva de tais iniciativas.

A construção social da ideia do cientista aliado ao desenvolvimento nacional vai ser formada ao se enfatizar que a competência e alta tecnologia estavam a serviço das necessidades do país. Em nossa pesquisa identificamos que a imprensa teve um papel de destaque na vulgarização desse conceito, publicando semanalmente artigos sobre tais questões.

Na matéria de jornal na qual se descreve os trabalhos realizados no laboratório do Departamento de Estado Sólido e Ciências de Materiais 플 vimento da tecnologia em transmissões em fibras óticas, é apresentado como um cientista que, além da competência e erudição inquestionáveis, também se mostrava capaz de usar da criatividade e improvisação necessárias às condições do desenvolvimento de pesquisas em alta tecnologia no território nacional.

Para ilustrar essa proposição, o repórter descreve o ambiente do laboratório e a atuação do cientista. Ao apresentar os procedimentos de realização de uma complexa experiência com raio laser, relata como uma solução inusitada foi encontrada para resolver um intricado problema que atrapalhava 0 andamento dos trabalhos, o uso de um simples secador de cabelos. 0 título da reportagem também transmite esse ideal de autossuficiência e adaptabilidade própria do brasileiro -"Difícil é o ar condicionado" - na frase temos uma referência espirituosa ao fato de que o pesquisador carregava para todos os lados o manual de instruções do ar condicionado do laboratório, equipamento que se recusava a funcionar corretamente. Essa era a grande preocupação do cientista diligente, conforme o repórter ${ }^{30}$. A matéria dá a entender que a pesquisa e desenvolvimento da mais alta tecnologia em comunicações da época era algo relativamente fácil para a equipe.

Podemos propor algumas explicações para o uso de tais inferências. Em um país que ainda não tinha formado uma tradição de pesquisa em alta tecnologia - e ao propormos essa premissa não estamos ignorando os enormes esforços empreendidos pelos cientistas precursores das décadas anteriores, e sim assinalando ao fato reconhecido pela historiografia de que o campo da C\&T nas décadas anteriores aos anos 60 era fragmentário - e devido aos altos custos envolvidos, era preciso preparar o público para às potencialidades e particularidades da atividade científica.

Apresentar a competência inquestionável de um pesquisador brasileiro com experiência na maior instituição de pesquisa do mundo, o Bell Laboratories, e descrever a maneira segura e confiante com que adapta seus conhecimentos às particularidades nacionais, é uma forma inteligente de se colocar essa questão. A construção do Brasil Potência forçosamente não poderia prescindir da habilidade e sofisticação que o cientista em questão apresentava. Essa é a conclusão inevitável do resultado da reportagem¹.

Ao mesmo tempo em que o conteúdo tecnológico é utilizado para seduzir a imaginação do leitor, também serve como argumento justificador para o público, que em última instância estava financiando essa custosa aposta. Conforme lembrava Cerqueira Leite em sua fala, a população inevitavelmente sofreria com esse sacrifício econômico. Apresentando a aposta do desenvolvimentismo tecnológico, ressalta-se que, apesar dos sacrifícios, ao menos a população poderia se sentir despreocupada quanto aos resultados do empreendimento, pois a tarefa tinha sido entregue em boas mãos.

De fato, o resultado desse investimento logo começou a aparecer. 0 Departamento de Estado Sólido e Ciência dos Materiais aprofundava consistentemente suas pesquisas teóricas e experimentais sobre os fenômenos ópticos e sobre materiais semicondutores. Nesse meio tempo, os cientistas envolvidos nessas pesquisas cogitavam como os resultados dos trabalhos poderiam ser utilizados no desenvolvimento de equipamentos de telecomunicações. Tais 
descobertas receberam divulgação da grande mídia, que ao anunciar os constantes avanços das pesquisas, resgatava a origem do processo na decisão do reitor Zeferino Vaz em repatriar os cientistas brasileiros no exterior ${ }^{32}$.

Em 18 de julho de 1973, graças às iniciativas do professor Ripper, a Unicamp assinou um convênio com a Telebrás no qual se procurou realizar um dos objetivos do Plano Básico de Desenvolvimento Científico e Tecnológico, 0 aprimoramento da tecnologia em telecomunicações. A contribuição do Laboratório de Pesquisas em Dispositivos seria aprofundar as investigações que estavam em andamento sobre 0 uso de lasers e semicondutores. Além de transferir 0 resultado dessas pesquisas para a Telebrás desenvolver industrialmente equipamentos de telecomunicações baseados nessas tecnologias. Conforme anunciado na época, a equipe de pesquisadores desenvolveria a tecnologia que tornaria viável economicamente a comunicação por fibras óticas no país ${ }^{33}$.

A partir de 1974, o Ministério das Telecomunicações e a Telebrás começaram a planejar a criação de uma instituição voltada a P\&D em telecomunicações. A cidade de Campinas tornou-se atrativa graças ao bom andamento do convênio assinado no ano anterior e às gestões junto aos órgãos decisórios promovidas pelo professor Ripper e o reitor Zeferino Vaz. Dispostos a atrair essa instituição de pesquisa para a cidade, esses acadêmicos procuraram o então Ministro das Comunicações, Euclides Quandt de Oliveira, e o presidente da Telebrás, o general José Antônio de Alencastro e Silva, convencendo-os da viabilidade da instalação do centro de pesquisa em Campinas 34 .

A argumentação utilizada tanto enfatizou a qualidade das instituições de pesquisa atuantes na cidade, em especial o êxito alcançado pelo convênio da Telebrás com a Unicamp, quanto a estrutura urbana e industrial favoráve ${ }^{35}$. Tal argumentação fazia muito sentido, pois a cidade, nesse momento, favorecia-se da crescente capacidade do setor de C\&T e P\&D, ao mesmo tempo em que herdara de seu legado histórico o processo de ordenação urbana e estruturação da indústria graças a evolução econômica da região associada a economia cafeeira e posteriormente industrial. Tais atributos despontavam como predicados inegáveis.

Em 1976, a Telebrás instalou em Campinas o Centro de Pesquisa e Desenvolvimento Padre Roberto Landell de Moura (CPqD). A partir de 1977, a pesquisa que vinha sendo realizada na Unicamp sobre 0 uso de fibras de vidro na transmissão da comunicação com laser começou a ser transferida para o CPqD. Doravante, a instituição deveria desenvolver o processo industrial de produção dessa tecnologia e transmitir esse conhecimento para empresas do setor tecnológico. Em 1979, a universidade começou o processo de transferência da tecnologia de produção dos lasers ${ }^{36}$.

Os resultados do convênio com a Telebrás não ficaram restritos às contribuições do Instituto de Física. Podemos citar também a atuação do Departamento de Engenharia Elétrica, que graças às equipes coordenadas pelos professores Rege Scarabucci e Dalton Soares Arantes, produziram diversos sistemas de transmissão de comunicação, tanto sistemas analógicos, quanto sistemas digitais, inclusive desenvolveram equipamentos para a transmissão de comunicação por fibras óticas ${ }^{37}$.

Na Faculdade de Engenharia Civil, Arquitetura e Urbanismo (FEC/Unicamp), a área de materiais, coordenada pelo professor Maurício Prates de Campos Filho, desenvolveu pesquisas no âmbito da química dos silanos. Uma das necessidades da Telebrás era a de absorver a tecnologia de fabricação desse componente químico para realizar a produção industrial de equipamentos eletrônicos. A equipe liderada pelo professor Campos Filho encaminhou o desenvolvimento dessa tecnologia ${ }^{38}$.

Além dos inúmeros desenvolvimentos tecnológicos, dos quais citamos alguns, o convênio com a Telebrás também foi responsável pela formação de muitos mestres e doutores graças aos programas de pesquisa que se iniciaram. Até 0 ano de 1980, já se contava trinta dissertações de mestrado e três teses de doutorado defendidas graças a essas pesquisas ${ }^{39}$. Esses números eram consideráveis para a época, principalmente tendo em conta a urgente necessidade de expansão da pesquisa em C\&T no país, especialmente nos setores de infraestrutura e tecnologia.

Ainda sobre a estrutura de formação científico/acadêmica, é preciso ressaltar o papel da Pontifícia Universidade Católica de Campinas (PUC-Campinas), que principalmente com os cursos de engenharia, formou profissionais que tiveram atuação nas instituições de pesquisa tecnológica e desenvolvimento do polo da cidade. 
Além do CPqD, a cidade de Campinas incorporou outras instituições voltadas à pesquisa. Em 1963, graças à iniciativa do governo do Estado de São Paulo, instalou-se na cidade o CPTA (Centro Tropical de Pesquisas e Tecnologia de Alimentos), atual ITAL (Instituto de Tecnologia de Alimentos). 0 objetivo do trabalho dessa instituição era promover atividades de P\&D e assistência tecnológica para empresas do setor alimentício.

Também se destacou entre as instituições de pesquisa da cidade o Centro de Tecnologia da Informação Renato Archer (CTI). Tal instituição começou a ser planejada no início dos anos 80 graças à atuação do professor José Ellis Ripper, que com apoio da UNICAMP, conseguiu atrair investimentos para a criação de uma instituição voltada à P\&D e fabricação de circuitos integrados em Campinas ${ }^{40}$. A escolha da cidade novamente se deu graças ao andamento das pesquisas em semicondutores, promovida pelo Instituto de Física, a presença de profissionais capacitados formados nessas instituições de ensino superior da região, além da qualidade de vida e facilidades urbanas encontradas em Campinas.

As primeiras atividades da instituição começaram em 1983, e na estreia dos trabalhos da fábrica de circuitos integrados do CTI, em depoimento para a imprensa, o então diretor geral da instituição, José Rubens Dória Porto, e 0 diretor do Instituto de Microeletrônica, Carlos Inácio Mammana, projetavam a fabricação de circuitos integrados de alta confiabilidade. Imaginavam em pouco tempo ter condições de produzir esse componente eletrônico em larga escala, inclusive fornecendo essa tecnologia para o uso em computadores de grande porte e equipamentos militares ${ }^{41}$.

Até agora pudemos perceber o surgimento de uma estrutura voltada à P\&D graças à presença ostensiva do Estado. Ou seja, todas as instituições voltadas a P\&D e C\&T apresentadas até esse momento surgiram como iniciativa do Governo Federal, e no caso do ITAL, por intermédio do governo do Estado de São Paulo.

Entretanto sabemos que para se configurar um polo tecnológico, além do necessário ambiente de pesquisa, condição suprida pelas universidades e instituições de P\&D atuantes da cidade de Campinas, é necessária a interação com 0 setor produtivo. Essa interação era facilitada pelo CPqD e pelo CTI, conforme vimos, e também por estruturas de apoio e incentivo ao desenvolvimento de indústrias tecnológicas que começam a surgir no final da década de 70 graças à iniciativa individual de alguns professores da UNICAMP. Nesses casos, não vemos a presença do Estado, e sim a ação particular de sujeitos ligados a C\&T na cidade de Campinas.

Sobre essas estruturas de apoio às indústrias tecnológicas estamos nos referindo ao surgimento da CODETEC (Companhia de Desenvolvimento Tecnológico) e da CIATEC (Companhia de Desenvolvimento do Polo de Alta Tecnologia de Campinas). Ambas as instituições surgem a partir da avaliação feita por alguns pesquisadores e professores da Unicamp da necessidade de espaços que permitissem a consolidação de algumas iniciativas individuais que estavam proporcionando 0 surgimento de pequenas indústrias de tecnologia na cidade ${ }^{42}$. A ideia por trás da criação dessas instituições era garantir o desenvolvimento dessas pequenas empresas, mais ou menos como o Stanford Industrial Park atuou no início das indústrias do Vale do Silício.

Inicialmente, a meta de consolidação da indústria tecnológica na cidade foi elaborada a partir da ideia da construção de uma incubadora de projetos industriais. Tal conceito, empregado largamente na atualidade, nos anos finais da década de 70 era uma ideia nova que precisava ser experimentada. 0 professor, Rogério C. Cerqueira Leite, do Instituto de Física, e Aldo Viera da Rosa, oficial reformado da aeronáutica, e então professor da Universidade de Stanford, começaram a elaborar o projeto no qual imaginavam uma estrutura dentro do Campus da Unicamp capaz de absorver e desenvolver projetos tecnológicos que estavam na fase de pesquisa dentro das unidades da universidade, transformando tais projetos em potenciais empresas ${ }^{43}$.

A partir de 1977, Cerqueira Leite começou as tratativas no sentido de instituir essa incubadora de indústrias, que foi nomeada como Companhia de Desenvolvimento Tecnológico (CODETEC). Nesse momento, negociava-se com a Finep, que entraria como uma das financiadoras do projeto, e naquele momento o professor Cerqueira Leite entendia ter boas perspectivas de conseguir esse apoio financeiro, já que José Pelúcio Ferreira, presidente da instituição, se mostrava empolgado com a ideia. 
Nessa época, em depoimento ao CPDOC/FGV, Cerqueira Leite afirmou: “Eu não posso dizer que a Codetec foi feita para criar indústrias, parece muito pretensioso. Mas ela vai criar uma indústria, eu garanto. Vai ajudar a criar algumas indústrias para o país, vai acelerar o process $0^{44 " .}$

Para presidência da CODETEC escolheram Aldo Viera da Rosa, e para o conselho de administração, convidaram diretores de grandes empresas brasileiras de capital nacional, como a Eletrometal e a Vilares, assim como alguns bancos ${ }^{45}$. Os primeiros projetos que começaram a ser desenvolvidos pela CODETEC eram frutos dos trabalhos de um grupo de pesquisa que recebia financiamento da Finep para desenvolver estudos sobre energia alternativa na Unicamp. Cabe lembrar que a partir de 1973, uma das grandes preocupações do planejamento econômico do Brasil, era encontrar maneiras de impedir a fuga de divisas para o exterior. A alta do preço do barril do petróleo consumia os recursos do país. Nessa conjuntura de crise, uma das respostas do governo foi apoiar a P\&D de tecnologias voltadas à produção de energia alternativa no Brasil. Um dos órgãos financiadores dessa empreitada foi a Finep, e graças à disponibilidade de investimentos para esse setor, as universidades começaram a desenvolveram projetos dentro dessa linha de pesquisa.

Na Unicamp, em resposta a demanda por pesquisas na área de energia, João Alberto Meyer, formou e passou a coordenar o Grupo de Energia, que se destacou na produção de pesquisas sobre energias renováveis e temas correlatos. Participavam desse grupo professores e alunos de diversas unidades da Unicamp. Parte das pesquisas desenvolvidas pelo Grupo de Energia foi utilizada como base para projetos de desenvolvimento de produtos industriais pela CODETEC. Podemos citar as pesquisas sobre energia solar, que proporcionaram o desenvolvimento de coletores de energia solar para 0 aquecimento de água. Também as pesquisas sobre biomassa, que encontraram aplicações práticas no desenvolvimento de grandes secadores de grãos baseados no sistema de bioconversão. Outro exemplo que pode ser citado está nas pesquisas que investigavam o fenômeno de eletrólise da água. Na CODETEC, com a coordenação do professor Saul Gonçalvez d'Ávila, baseando-se nos resultados dos estudos sobre eletrólise, desenvolveram um módulo industrial utilizando essa tecnologia. Graças às potencialidades apresentadas naquele momento, o desenvolvimento desse equipamento atraiu uma linha de crédito financiada pela CESP (Companhia Energética de São Paulo), que se mostrou interessada em aprimorar essa tecnologia. Para concluir, imaginava-se também a aplicação de eletrolisadores para a fabricação de amônia. Tal projeto concebia a criação de grandes usinas que utilizariam hidrogênio eletrolítico para a fabricação desse composto. Esse projeto, imaginado por Aldo Viera da Rosa, nunca avançou além da fase de planejamento devido aos enormes custos com a usina e com a infraestrutura necessária ${ }^{46}$.

Estamos citando algumas das diversas tentativas de desenvolvimento de produtos voltados à substituição de energia. Desses projetos, algumas tecnologias foram materializadas no desenvolvimento de produtos industriais. Tais produtos, inclusive, proporcionaram o aparecimento de algumas pequenas empresas, como, por exemplo, a Codesol, empresa especializada na produção de coletores de energia solar para aquecimento. Também podemos citar a Termoquip, empresa que se especializou na produção de grandes gaseificadores industriais. 0 elemento comum a essas indústrias é a produção de equipamentos simples, baseados em tecnologias que não exigissem grandes investimentos.

Além das pesquisas voltadas ao desenvolvimento de produtos na área de energia, na primeira metade da década de 1980, a CODETEC tentou incubar grandes projetos para áreas estratégicas da economia nacional. Podemos citar um projeto de uma fábrica de fibras óticas que seria construída na cidade, ou a investida no setor farmacêutico, projeto no qual se pretendia fabricar os fármacos utilizados na produção de medicamentos. A tentativa de se criar uma fábrica de fibras óticas não foi adiante devido à falta de investimentos privados e a concorrência de grandes companhias que se instalaram na cidade ${ }^{47}$. A produção de fármacos não avançou além do início da década de 1990, em parte devido à abertura de mercado promovida pelo governo Collor (1990-1992) e a concorrência com as grandes empresas farmacêuticas internacionais ${ }^{48}$.

A segunda iniciativa que tentou apoiar e estruturar o desenvolvimento de empresas de tecnologia na cidade foi 0 movimento de criação de um parque tecnológico planejado para ser instalado na área de intersecção entre a Unicamp e o CPqD.

Nos anos finais da década de 1970, e início dos anos 80, a área entre a universidade e a instituição de pesquisa da Telebrás ainda não estava ocupada. Graças à experiência de Aldo Viera da Rosa, professor em Stanford e profundo 
conhecedor do processo técnico-industrial em andamento no Vale do Silício, Rogério C. Cerqueira Leite começou a elaborar um projeto de instalação de um parque tecnológico nas imediações da Unicamp inspirado no desenvolvimento das atividades do Stanford Science Park. Nessas primeiras elucubrações, imaginava-se um local para acolher as empresas de tecnologia que surgiriam como resultado das pesquisas que estavam sendo desenvolvidas pelo CPqD e Unicamp. Planejava-se uma situação onde o apoio da prefeitura permitiria que empreendedores e investidores pudessem implementar empresas de tecnologia. Essas empresas se desenvolveriam graças à disponibilidade de terras a baixo custo - subsidiadas pelo governo local - e a presença próxima das instituições de P\&D que atuariam em colaboração com a indústria local $\stackrel{49}{ }$.

Esse projeto foi apresentado ao reitor Zeferino Vaz que apoiou a iniciativa junto à administração municipal ainda no ano de 1976므. Entretanto as conversas só conseguiram avançar quatro anos depois na gestão do prefeito José Roberto Magalhães Teixeira.

Em 1981, o prefeito Magalhães Teixeira assinou o decreto 6619 delimitando o zoneamento da área no entorno da universidade para as indústrias tecnológicas. Conforme a justificativa apresentada no decreto, a presença próxima às instituições de pesquisa e universidades era uma condição fundamental para o bom encaminhamento de projetos que procurassem integrar as pesquisas desenvolvidas no âmbito da universidade e instituições de P\&D, com o setor produtivo. A lei estabelece o zoneamento especial da área onde pretende-se instalar o parque tecnológico e define 0 objetivo de replicar a estrutura técnico-científica inicialmente desenvolvida no Vale do Silício na cidade de Campinas.

Além da lógica de concentração espacial dos meios de produção e conhecimento, também se justifica o projeto recorrendo-se a argumentos que mobilizam a ideia do desenvolvimento econômico local e as pretensas vantagens ecológicas desse arranjo produtivo - cabe lembrar que nos primórdios da indústria eletrônica, uma noção vulgarmente difundida por gestores e políticos ao divulgar as vantagens dos processos produtivos constituintes da fabricação de equipamentos eletrônicos, seriam os supostos aspectos ecológicos que envolveriam essa indústria que começava a receber o questionável rótulo de não-poluente.

Em depoimento a um veículo de comunicação, o prefeito Magalhães Texeira afirmou: “0 município está interessado no projeto porque paralelamente aos benefícios às indústrias a cidade também ganharia com a criação de mais empregos e mais arrecadação, evitando-se também problemas ecológicos, pois as firmas não são poluentes" esse depoimento vemos a conjunção do pragmatismo planejador, que avalia o desenvolvimento da indústria local como fonte de arrecadação e emprego, com a utopia ligada ao desenvolvimento tecnológico. Imagina-se que a indústria eletrônica representava uma alternativa econômica altamente recomendável, pois essa indústria conciliaria as demandas do desenvolvimento com as necessidades ecológicas.

A partir desse depoimento, a conjunção dos motivos ecológicos e econômicos passou a ser utilizado como principal fio condutor das explicações em torno da criação dessa unidade produtiva. Nas reportagens veiculadas pela imprensa sobre desenvolvimento do parque tecnológico, que em 1981 era nomeado como Intercamp, recorreu-se a justificativas que utilizavam conteúdos centrados na aposta tecnológica, na busca por uma nova indústria não poluente e nos potenciais ganhos locais previstos nesse process $0^{52}$.

Apesar da inicial empolgação em torno do desenvolvimento de mais uma unidade produtiva voltada à alta tecnologia na cidade, o processo de instalação desse parque tecnológico se mostrou bem mais complicado que o imaginado. Somente dois anos após o decreto da prefeitura zoneando a área urbana destinada à indústria tecnológica é que se estruturou a uma instituição responsável por coordenar a implementação das empresas no parque tecnológico imaginado. Criou-se assim, em 1983, o Centro de Indústrias de Alta Tecnologia. Esse projeto continuou em desenvolvimento até 1985, quando o CPqD, o CTI e a CPFL (Companhia Paulista de Força e Luz) ingressaram no planejamento do parque tecnológico, formando a Companhia de Desenvolvimento do Polo de Alta Tecnologia de Campinas (CIATEC). A CIATEC passou a ser gerida funcionalmente por uma empresa de sociedade anônima de economia mista (municipal e particular), a IMA (Informática dos Municípios Associados S/A), e a CODETEC. 
A nossa pesquisa identifica que muito da demora em se estruturar o projeto do parque tecnológico deveu-se à burocracia e interesses divergentes dentro do governo municipal ${ }^{53}$. Ficou evidente a existência de antagonismos quanto aos rumos do parque tecnológico no momento em que essa unidade econômica começou a se configurar em 1986. Comparando o projeto inicial com a estrutura instalada, percebe-se um contraste evidente. Ao invés de um espaço onde a pequena e média indústria poderiam se inserir, a unidade nomeada Polo I colocou à venda uma área que permitia a instalação de 49 grandes empresas, disponibilizando lotes de no mínimo $10.000 \mathrm{~m}^{2}$. Esses lotes foram vendidos a preço de mercado.

Ou seja, a ideia de apoiar as iniciativas locais voltadas a projetos pioneiros de P\&D abriu espaço a um conceito articulado às necessidades das grandes empresas de tecnologia já consolidadas. 0 caráter especulativo desse empreendimento também foi detectado, pois os preços eram pouco acessíveis ao pequeno empreendedor ${ }^{54}$.

Mesmo a localização do Polo I fugiu da inicial configuração imaginada próxima à universidade. A área de instalação desse primeiro parque tecnológico se situou próximo ao CTI, que geograficamente encontrava-se a uma distância de aproximadamente 10 quilômetros da região inicialmente projetada. A área próxima à universidade só foi ocupada nos anos 90, quando a CIATEC abriu o empreendimento que foi nomeado como Polo II.

Do ponto de vista quantitativo, conforme extensa pesquisa realizada pelo pesquisador Paulo Roberto Joia, considerando as indústrias instaladas nas unidades Polo I e Polo II, a CIATEC, até o final da década de 1990, não conseguiu atrair mais de 20 empresas para os parques tecnológicos sobre sua administração. $\frac{55}{5}$ Se o desenvolvimento da CIATEC foi prejudicado pela desarticulação entre planejadores, burocracia municipal e o setor produtivo, vemos que a própria estrutura de C\&T, que surgiu graças às ações do governo federal na cidade, viu-se debilitada nos anos em que o Modelo Brasileiro de Desenvolvimento, e o próprio regime militar, entraram em decadência.

Os sinais de esgarçamento do apoio federal às iniciativas locais já eram constatados, mesmo que de uma maneira indireta, ainda no fim da década de 1970. A percepção de uma crise estrutural pode ser notada em um depoimento dado à imprensa por Rogério C. Cerqueira Leite, em setembro de 1979. Ao participar de uma mesa de debates sobre a crise na UNICAMP causada por cortes orçamentários promovidos pelo governador Paulo Maluf, Cerqueira Leite ponderou que a excessiva dependência do governo estava condicionando limites estreitos às possibilidades da universidade. Também citou a inexistência de uma iniciativa privada vigorosa como um entrave a avanços mais significativos na relação entre as universidades e 0 setor produtivo. Descrevendo esse contexto, 0 intelectual apresenta as dificuldades que estava enfrentando para consolidar a CODETEC:

Isso não funcionou [referindo-se à CODETEC] porque os empresários estão mais ligados ao governo, de quem dependem, do que às universidades. Quando a universidade surgiu no mundo servia apenas a uma elite de intelectuais. Atualmente, apesar de suas novas funções, ela tem sempre um pacto com o poder não explícito, mas que existe ${ }^{56}$.

Se retomarmos a análise desse artigo, veremos que o pacto não explícito com o poder permitiu o surgimento de uma considerável estrutura de P\&D na cidade de Campinas. Conforme vimos, essa estrutura foi criada graças à articulação dos projetos da universidade com a política desenvolvimentista do regime militar. Entretanto, quando 0 ufanismo propagador da ideia do "Brasil Potência" viveu seu crepúsculo, e o planejamento econômico do governo precisou lidar com uma situação de grave crise econômica, nesse momento, o governo abriu mão de qualquer pretensão desenvolvimentista. A partir de então, o pacto não explícito com o poder começou demonstrar suas facetas negativas.

Em uma situação de grave crise econômica, o regime militar precisou abandonar as pretensões desenvolvimentistas e se voltar para o pragmatismo de uma realidade pouco favorável. 0 objetivo do planejamento econômico passou a ser modesto, garantir um término de governo estável. Para cumprir essa meta, o regime militar submeteu-se ao FMl, desmobilizando toda a estrutura desenvolvimentista que estava em curso. 
Campinas ainda colheu dividendos de um momento anterior, quando inaugurou projetos que tinham começado em uma conjuntura econômica mais favorável. A inauguração do CPOd e do CTI aconteceu nesse contexto. Mas esses foram os últimos lampejos do projeto desenvolvimentista que mobilizou grande parte da imaginação e sonhos da década anterior.

0 próprio presidente Figueiredo confirmou esse prognóstico quando visitou CPQd, em 1980, nessa visita confidenciou aos repórteres presentes: "0 que falta para o Brasil são os recursos, pois dentro de três anos essa rapaziada da Telebrás estará dominando a tecnologia, mas não temos recursos para implementar as necessidades da telecomunicações ${ }^{\prime \underline{57}}$. Ao ser questionado se era viável aumentar o grau de prioridade para a P\&D, o então presidente se esquivou: "Não é possível porque todos os setores são prioritários" 58 .

A inconstância de investimentos, que começava a transparecer no início da década de 1980, a partir de então, aos poucos, se tornou uma norma. A desmobilização do sistema de C\&T foi tão significativa que meses após o fim do regime militar, uma das principais instituições de P\&D da cidade de Campinas, o CTI, não tinha nem confirmação da dotação orçamentária que dispunha para concluir o ano de 1985. Naquele momento, essa instituição empregava mais de trezentas pessoas. Entre esses funcionários estavam presentes vinte doutores, trinta e seis mestres, e diversos técnicos de nível médio e superior. Além de pagar seus funcionários, a instituição estava responsável por dar andamento a vinte projetos voltados a C\&T $\underline{59}$.

Vivendo tal situação de precarização, a atividade P\&D, que nos anos anteriores podia ter se inspirado no pensamento utópico, a partir de então passou a viver as agruras da restrição de gastos. Simplesmente não havia recursos para a realização das atividades científicas no país.

A Finep, uma das grandes fomentadoras dos projetos desenvolvidos em Campinas, nessa conjuntura, restringiu grande parte dos investimentos destinados à P\&D. Em conversa com o um membro da administração dessa instituição, o diretor-geral do CTI, Miguel Teixeira de Carvalho, ouviu o seguinte pensamento: "Se der muito dinheiro a um órgão de pesquisa, ele acaba pesquisando máquina de desentortar banana" ${ }^{\prime 60}$. Essa frase é mais do que exemplar de um novo momento onde se abandonou completamente a perspectiva de apoio às potencialidades transformadoras da C\&T.

A obrigatória mudança de curso pela qual passaram as instituições de P\&D da cidade no início da década de 1990, conforme aponta a pesquisa de Paulo Roberto Joia ${ }^{61}$, já era percebida nessa circunstância. Em depoimento sobre as condições do CTI, nesse ambiente de restrição econômica, o diretor-geral dessa instituição, afirmou: "Com pouco dinheiro só se pode fazer uma solução se alguém precisa dela. Então o CTI vai precisar trabalhar em conjunto com outros órgãos e empresas. Se o trabalho proposto interessa aos outros aparecem recursos" $\underline{62}$.

Outro indicador que podemos usar como referência do grau de desmobilização que a estrutura de CধT estava enfrentando, está na formação de um sindicato de trabalhadores prestadores de serviços para instituições de C\&T. Em 1990, a cidade de Campinas torna-se sede do Sindicato de Trabalhadores de Pesquisa, Ciência e Tecnologia do Estado de São Paulo (SINTPq). Nesse momento, a principal preocupação da categoria era o temor de possíveis ameaças de desemprego e desestruturação das instituições de P\&D públicas. No horizonte de curto prazo, algumas das instituições de pesquisa da cidade foram privatizadas ou passaram por rigorosos processos de contensão de gastos e consequentes demissões. $\underline{\underline{63}}$

No final desse processo vemos que a pesquisa em C\&T passou a ser planejada longe das pretensões desenvolvimentistas. A partir de então, um novo arranjo econômico passou a impor suas demandas e compromissos. Nesse contexto, o polo tecnológico de Campinas se reconfigurou para atuar dentro dessa nova lógica.

\section{Conclusões}

Ao abordarmos o surgimento de um polo tecnológico em Campinas, nossa análise privilegiou avaliar como as dinâmicas históricas locais criaram condições para que projetos e ideias exteriores às dinâmicas da região fossem acolhidos e estruturassem uma nova etapa econômica na cidade. 
No tocante ao campo da C\&T, área determinante para o surgimento de um polo tecnológico, podemos verificar na historiografia que aborda essa questão que desde a etapa agrícola, a relação entre a estrutura de P\&D e o setor produtivo sempre foi próxima. Tal articulação inicialmente foi proporcionada pelas atividades do IAC ${ }^{64}$, posteriormente a Unicamp assumiu esse mesmo perfil ao determinar que um dos seus objetivos fundamentais era o de buscar soluções às demandas sociais através do ensino e pesquisa científica ${ }^{65}$. Nesse momento de formação, a universidade voltou-se aos grandes problemas nacionais e dessa iniciativa as estruturas de P\&D do polo tecnológico foram constituídas.

Cabe também ressaltar que a ideia de criação de uma unidade produtiva baseada no conhecimento técnico científico foi implementada em Campinas graças à atuação científica de alguns professores da Unicamp. Tais professores ao se fixarem na cidade trouxeram, junto de sua bagagem intelectual, um modelo de produção ainda não implantado na região, mas muito bem-sucedido em algumas áreas dos Estados Unidos. Da tentativa de transplantar tal estrutura produtiva para a região, criou-se um polo tecnológico.

É importante observar que a existência da estrutura de P\&D mobilizada na construção do polo tecnológico só foi possível graças a uma conjuntura política singular. 0 regime militar incorporou ao planejamento econômico a necessidade de aproximação com a C\&T. A partir de então, disponibilizou-se recursos para projetos de pesquisa que se voltassem ao desenvolvimento de tecnologias necessárias ao crescimento econômico do país. Conforme nossa pesquisa demonstrou, o Estado instalou na região de Campinas uma grande estrutura de P\&D para apoiar o seu projeto desenvolvimentista. Também demonstramos que a participação ativa de pesquisadores/professores da Unicamp foi fundamental para a criação e desenvolvimento dessa estrutura.

Avaliando em sua origem, podemos dizer que o a formação do polo tecnológico de Campinas é resultado do Modelo Brasileiro de Desenvolvimento, conforme o planejamento elaborado pelo regime militar. Tal afirmativa se justifica ao observamos que o setor de P\&D se constituiu em torno dos projetos desenvolvimentistas do governo. Outro ponto que demonstra essa questão é a constatação de que a ligação com as demandas governistas se mostrou extremamente limitadora em um momento de desarticulação da estrutura desenvolvimentista.

Acreditamos que se compararmos o projeto de Campinas com o modelo mundial de polo tecnológico, o Vale do Silício, veremos que a estrutura desenvolvida nessa região nunca se assemelhou a sua fonte inspiradora. Principalmente devido à pequena participação da iniciativa privada, limitado alcance do empreendedorismo, e claro, a inexistência de massivos investimentos públicos nas pesquisas desenvolvidas pelas instituições de C\&T locais. A escala do potencial de subsídio do governo estadunidense não pode ser comparada ao limitado alcance do governo brasileiro naquela conjuntura.

Por outro lado, não é exagerado afirmar que, em sua origem, existiam elementos muito interessantes sendo conjugados nesse polo tecnológico. Especialmente se considerarmos que, da estrutura de P\&D desenvolvida na cidade, o país passou a possuir tecnologia própria para a fabricação de mais de uma centena de produtos nas áreas de telecomunicações, microeletrônica, medicamentos, química e setor metal mecânico, graças às empresas de alta tecnologia do Polo Tecnológico de Campinas.

A crítica elaborada pela bibliografia que analisa a estrutura desse polo tecnológico se concentra em observar que essa capacidade industrial não pode ser plenamente aproveitada pela indústria nacional. 0 fim da reserva de mercado e da lei de informática abriu espaço para o avanço das multinacionais. Essas indústrias não desenvolviam suas principais tecnologias na região por contarem com laboratórios de P\&D instalados nos grandes polos tecnológicos dos países centrais. Nesse meio tempo, as indústrias locais de tecnologia passaram a ser simples produtoras de equipamentos e/ ou softwares terceirizados pelas grandes companhias internacionais, ou então ocuparam o mercado montando produtos tecnológicos fabricados no exterior. Tais empresas nacionais instaladas em Campinas apresentaram uma tendência de se afastar cada vez mais da estrutura de P\&D presentes na cidade, concomitantemente, a estrutura voltada a amparar as empresas de base tecnológica não conseguiu recuperar 0 ambiente voltado a inovação e pesquisa tecnológica ${ }^{66}$.

Do ponto de vista social, observamos que a inicial expectativa em torno da nascente indústria tecnológica se mostrou exageradamente otimista quanto às possibilidades de crescimento econômico, geração de emprego e distribuição de renda para os habitantes desse polo tecnológico. Em 1995, a Fundação SEADE (Fundação Sistema Estadual 
de Análise de Dados) publicou um levantamento estatístico das condições de vida, saúde, educação e emprego da população campineira, esses dados refletem as condições existentes na cidade no ano de $1994^{67}$. Os resultados desse estudo confirmam algumas das hipóteses críticas quanto aos resultados econômicos e sociais de um polo tecnológico. Tal unidade produtiva, ao contrário da propagada noção de que eventualmente ajudaria a equilibrar as demandas sociais de um território, na verdade, em sua atuação, tende a acentuar o desenvolvimento desigual, no caso de Campinas, foi observado que às estruturas mobilizadas na constituição do polo diferenciaram e hierarquizaram o espaço, até mesmo gerando um crescente distanciamento entre os trabalhadores possuidores de conhecimento científico dos que não o possuem. Essa tese crítica aos resultados sociais dos polos tecnológicos, proposta por alguns trabalhos realizados principalmente no campo da geografia ${ }^{68}$, pode ser amplamente corroborada no levantamento realizado pelo SEADE.

No estudo publicado pelo SEADE fica evidente que após uma década de atuação do polo tecnológico a população da cidade ainda enfrentava os graves problemas de desigualdade social típicos da sociedade brasileira. Podemos citar alguns dados dessa pesquisa para comprovar tal afirmativa: considerando 0 acesso à educação, 40\% das famílias da cidade eram carentes de instrução - e nas famílias de situação econômica mais precária, 75\% desse grupo, não tinham concluído sequer os quatro primeiros anos do atual ensino fundamental. A presença de famílias negras era minoritária nos grupos sociais mais abastados $(4,7 \%)$, sendo proporcionalmente predominante nos grupos extremamente empobrecidos e em situação de miséria (37,1\% e 52,4\%, respectivamente). A distribuição de renda apresentava altos índices de concentração, uma família empobrecida dispunha de apenas $14 \%$ da renda de uma família abastada. Se considerarmos nas estatísticas a renda familiar per capita, as diferenças entre os grupos se amplificam, dado o fato das famílias empobrecidas, na média, possuírem mais membros. Se continuarmos esmiuçando os dados verificaremos uma sociedade onde crianças de famílias empobrecidas ainda eram responsáveis por parte significativa da renda familiar, onde mulheres negras e pardas recebiam rendimentos significativamente menores que mulheres brancas e amarelas, onde pais de família empobrecidos enfrentavam grandes dificuldades de inserção no mercado de trabalho e o emprego, quando conquistado, era caracterizado pela baixa renda e alta rotatividade, outro dado ilustrativo mostra que a infraestrutura dos bairros periféricos era consideravelmente inferior à dos bairros abastados, pois a população convivia com dificuldade em conseguir do poder público estruturas básicas, como asfalto e saneamento ${ }^{69}$.

Analisando esses dados, veremos que inúmeros elementos comprovam o caráter altamente desigual da região. Entretanto, nos chamou a atenção uma informação que em nossa perspectiva analítica demonstra o grau de cisão entre os trabalhadores que possuem o conhecimento científico, dos que não o possuem ${ }^{70}$ : no grupo $\mathrm{A}$ (grupo que pode ser definido como o extremo superior da escala econômica elaborada pelo SEADE, este grupo agregava 32,5\% das famílias de Campinas em 1994. Comparadas às demais, estas famílias possuem maior nível de instrução, condições habitacionais mais satisfatórias, menor vulnerabilidade de inserção no mercado de trabalho e renda per capita mais elevada) é bem mais expressiva a proporção de assalariados do setor público e de empregadores (incluídos os donos de negócio familiar e os professores universitários autônomos) e onde se observa a menor proporção de assalariados do setor privado, que não chega a $50 \%$.

Esses trabalhadores do grupo A, que ocupam lugar nas universidades, que realizam as atividades produtivas do polo tecnológico com suas empresas de médio e pequeno porte, que trabalham nas enfraquecidas, mas ainda existentes instituições de P\&D da cidade, socialmente se encontravam em uma situação de singularidade em relação ao seu entorno. Pois, apesar de enfrentarem os problemas do avanço das medidas neoliberais, ainda conseguiam se preservar das dinâmicas mais agressivas dessa nova etapa econômica. Viviam e trabalhavam em locais privilegiadas em relação à atenção do Estado, usufruindo de modo de vida pouco semelhante ao dos outros grupos sociais da cidade.

Dessa maneira, consideramos que a análise efetuada por Tavares, que avalia os resultados dos polos tecnológicos a partir do enfoque da reestruturação do espaço e do processo de concentração dos fatores de produção, extremamente ilustrativa para 0 entendimento de parte dos resultados dessa estrutura técnico-científica na cidade de Campinas.

Se buscarmos as discussões e projetos expostos no início da história dessa unidade produtiva, e se considerarmos os discursos que procuravam legitimar a construção do polo tecnológico, ou seja, se pensarmos no alcance 
desse projeto, que inicialmente foi concebido com muitos dos elementos de uma utopia técnico-científica, veremos que os custos sociais não retornaram os dividendos imaginados, nem para a indústria nacional de alta tecnologia, que se desmobilizou com o avanço do capital internacional, nem para a população local, que em sua maioria ficou alheia aos resultados positivos desse processo.

Tal desfecho, que pode ser enunciando como decepcionante, na verdade nos fornece a oportunidade de perceber dinâmicas históricas que passariam despercebidas caso a estrutura montada na região se configurasse um desmedido sucesso. Talvez uma das questões centrais desse processo esteja no próprio alcance das ideias e empreendimentos colocados em movimento na cidade de Campinas. Ver o fracasso do Modelo Brasileiro de Desenvolvimento planejado pelo corpo técnico-burocrático a servido do regime militar, e a consequente crise que se instalou no campo da C\&T, nos permite perceber como a marcha desenvolvimentista encetada no Brasil desse período estava em descompassado com as dinâmicas múltiplas e imprevistas das forças históricas. 0 planejamento estruturante, usando da planificação econômica, não conseguiu antever, ou mesmo responder pertinentemente as crises que abalaram a estrutura construída. Sobre essa questão o historiador E. Hobsbawm comenta: "A ciência social moderna, a política e o planejamento adotaram um modelo de cientificismo e manipulação técnica que, sistemática e deliberadamente negligencia o humano e, acima de tudo, a experiência histórica"ㄲ1․

Em Campinas fatores como a estrutura política local e seus conflituosos interesses, a dinâmica econômica nacional e suas limitações, a dependência universitária de um enfraquecido sistema de patrocínio a C\&̛T, são todos elementos que corroeram o processo desenvolvimentista tecnológico planejado. Tais elementos, quando não insuspeitos, não foram superados.

\section{Notas e referências bibliográficas}

Willian Gama dos Santos é mestre em História Social pela Universidade de São Paulo, pesquisador colaborador do Centro Interunidades de História da Ciência

1 Este artigo é resultado das discussões realizadas durante o desenvolvimento da dissertação de mestrado defendida no final do ano de $2017 \mathrm{na}$ Faculdade de Filosofia, Letras e Ciências Humanas - USP, Departamento de História Social - "A política de ciência e tecnologia e o modelo brasileiro de desenvolvimento na formação do polo tecnológico de Campinas" - e apresentado no "Simpósio USP de Ciência e Tecnologia: Construindo Diálogos Interdisciplinares". Agradeço a orientação e observações do Professor Shozo Motoyama durante a realização dos trabalhos. GUIMARÃES, E. A. A Política Científica e Tecnológica. Rio de Janeiro: Jorge Zahar, 1985.

3 BADARÓ, R. C. Campinas - 0 despertar da Modernidade. Campinas, CMU, Unicamp, 1996.

4 GOMES, E. J. A Experiência Brasileira de Polos Tecnológicos: Uma Abordagem Político Institucional. Dissertação (mestrado), Universidade Estadual de Campinas, 1996.

5 Idem.

6 Entrevista com Zeferino Vaz.

7 Idem.

$8 \quad$ Idem

$9 \quad$ Idem

10 RODRIGUES, M. L. V. Inovações no Ensino Médico e Outras Mudanças: Aspectos Históricos da Faculdade de Medicina de Ribeirão Preto. Medicina Ribeirão Preto, 2002.

11 JOIA, P. R. Novas Trajetórias da Alta Tecnologia no Brasil, Sob a Influência da Ação do Estado: Uma Análise do Polo Tecnológico Regional de Campinas-SP. Rio Claro, Universidade Estadual Paulista, Instituto de Geociências e Ciências Exatas, Tese (Doutorado), 2000.

12 Idem.

13 Entrevista com José Ellis Ripper.

14 Entrevista com Zeferino Vaz.

15 Entrevista com Rogério Cezar de Cerqueira Leite.

16 O Estado de São Paulo, 19 nov. 1972.

17 Entrevista com Rogério Cezar de Cerqueira Leite.

18 Entrevista com Zeferino Vaz. 
26 Como membro do conselho editorial do jornal Folha de São Paulo, Rogério C. de Cerqueira Leite produziu quantidade significativa de editoriais e artigos. Sobre o tema em questão citamos as seguintes edições desse veículo de imprensa: Folha de S. Paulo, 08 jul. 1976; Folha de S. Paulo, 19 nov. $1978 ;$ Folha de S. Paulo, 12 ago. 1979; Folha de S. Paulo, 06 nov. 1979; Folha de S. Paulo, 02 fev. 1970; Folha de S. Paulo, 05 abr. 1981; Folha de S. Paulo, 21 abr. 1981. Entrevistas com José Ellis Ripper; Rogério Cezar de Cerqueira Leite; Saul Gonçalves d'Ávila.

28 Entrevista com Saul Gonçalves d’Ávila.

29 O Estado de São Paulo, 26 nov. 1971.

30 Idem.

31 Idem.

32 O Estado de São Paulo, 18 nov. 1972; Folha de S. Paulo, 06 dez. 1980; Folha de S. Paulo, 03 jul. 1982; Folha de S. Paulo, 27 mar. 1982

33 O Estado de São Paulo, 18 jul. 1973.

34 Entrevistas com José Ellis Ripper; Zeferino Vaz.

35 Entrevista com Saul Gonçalves d'Ávila.

36 Folha de S. Paulo, 25 ago. 1979.

37 Folha de S. Paulo, 06 dez. 1980.

38 Entrevista com Saul Gonçalves d'Ávila.

39 Folha de S. Paulo, 06 dez. 1980.

40 Entrevista com José Ellis Ripper.

41 Folha de S. Paulo, 15 out. 1983.

42 Entrevista com Rogério Cezar de Cerqueira Leite.

43 Entrevista com Saul Gonçalves d’Ávila.

44 Entrevista com Rogério Cezar de Cerqueira Leite.

45 Entrevista com Saul Gonçalves d'Ávila.

46 Entrevista com Saul Gonçalvez d'Ávila.

47 Folha de S. Paulo, 15 ago. 1984.

48 Entrevista com Rogério Cezar de Cerqueira Leite; Entrevista com Saul Gonçalvez d'Ávila.

49 Entrevista com Rogério Cezar Cerqueira Leite.

50 Folha de S. Paulo, 03 out. 1981; Entrevista com Rogério Cerqueira Leite.

$51 \quad$ Folha de S. Paulo, 14 jun. 1981.

52 Folha de S. Paulo, 14 jun. 1981; Folha de S. Paulo, 03 out. 1981; Folha de S. Paulo, 19 ago. 1983; Folha de S. Paulo. 12 ago. 1985.

53 Entrevista com Rogério Cezar Cerqueira Leite.

54 Entrevista com Rogério Cezar de Cerqueira Leite.

55 JOIA, 2000.

$56 \quad$ Folha de S. Paulo, 20 set. 1979.

$57 \quad$ Folha de S. Paulo, 28 nov. 1980.

58 Idem.

59 Folha de S. Paulo, 18 set. 1985.

60 Folha de S. Paulo, 18 set. 1985.

61 JOIA, 2000.

62 Folha de S. Paulo, 18 set. 1985.

63 JOIA, 2000.

64 Algumas das principais obras que procuraram analisar o surgimento e atuação do IAC são: DANTES, M. A. 1979. Institutos de Pesquisa Científica no Brasil; IAC, 1987: Instituto Agronômico de Campinas:1887-1897: Tem História Pra Contar; MELONI, R. A. 1999. Ciência e Produção Agrícola. A Imperial Estação Agronômica de Campinas 1887/1897.

65 Entrevista com Zeferino Vaz.

66 Bibliografia sobre o polo de Campinas: DE MATTOS, M. 1990. Polos Tecnológicos: Um Estudo de Caso; GOMES, E. J. 1995. A Experiência Brasileira de Polos Tecnológicos: Uma Abordagem Político Institucional. GOMES, E. J. 1998. Imaginário e Realidade em Torno dos Parques e Polos Tecnológicos: Elementos 
Para Reflexão; JOIA, P. R. 2000. Novas Trajetórias da Alta Tecnologia no Brasil, Sob Influência da Ação do Estado: Uma Análise do Polo Tecnológico Regional de Campinas-SP; LIMA, L. C. 1997. Tecnopolo: A Formação de Uma Nova Territorialidade; SANTOS, R. C. B. 2005. Campinas Como Polo Tecnológico na Reestruturação do Espaço Urbano Regional; TAVARES, H. M. 1997. Complexos de Alta Tecnologia e Reestruturação do Espaço.

670 resultado desse estudo foi publicado em: SEADE. 1995. Pesquisa de Condição de Vida: Campinas, Primeiros Resultados.

68 TAVARES, H. M. Complexos de Alta Tecnologia e Reestruturação do Espaço. In: SANTOS, M.(org) et al. Fim de Século e Globalização. 3ed. São Paulo: Hucitec-Anpur, 1997.

69 SEADE. Pesquisa de Condição de Vida: Campinas, Primeiros Resultados, 1995.

70 Idem, p.70.

71 HOBSBAWM, Eric. Sobre História. São Paulo: Companhia das Letras, 2013, p. 48.

[Artigo recebido em Dezembro de 2019. Aceito para publicação em Março de 2020] 